\title{
A STUDY ON IMPROVING THE QUALITY OF STUDENT'S LEARNING STYLE BY USING VARK INSTRUMENTS - SPECIAL REFERENCE TO HOTEL MANAGEMENT CURRICULUM
}

Souji Gopalakrishna Pillai*

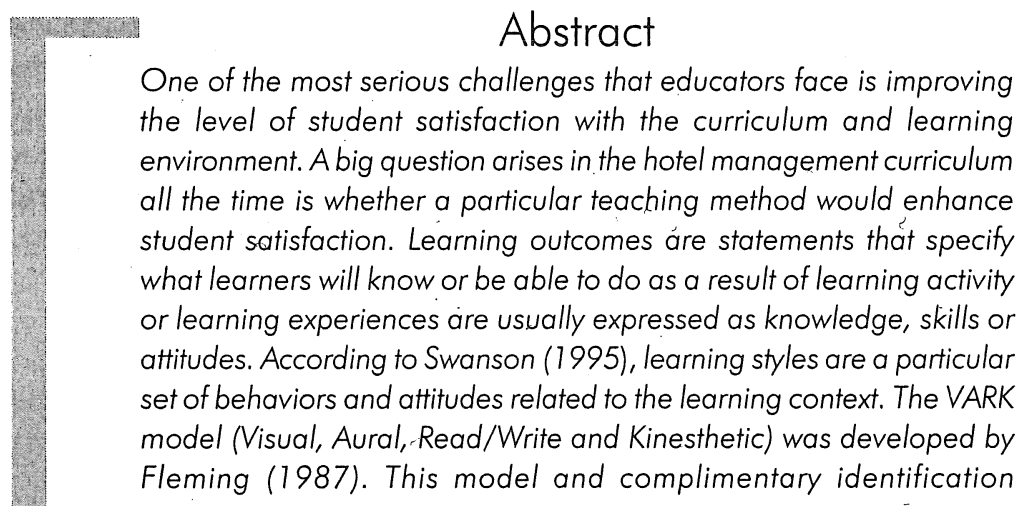

* Lecturer, School of Hospitality and Tourism, Taylor's University College, Malaysia. 


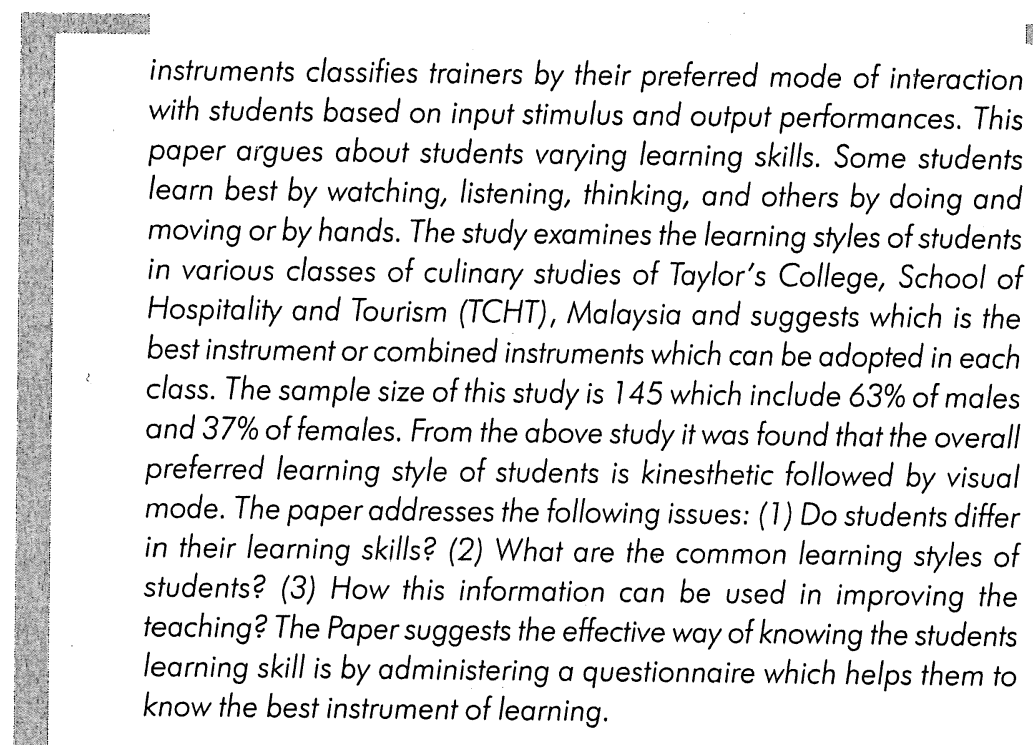

\section{Introduction}

A learning style or preference is the complex manner in which, learners most effectively and efficiently perceive, process, store and recall what they are attempting to learn. Today's students represent broad preferences in terms of age, experience, culture, ethnicity and level of preparedness as well as learning preferences and styles. The lack of regard for an individual learning style can cause a student's discomfort level to be great enough to hinder or prevent learning. In the constructiveness theory, Felder (1996) introduces the idea of how the learner is intrinsic to the learning experiences. Construction of knowledge by making sense of experiences in terms of what is already known is discussed by Brandt (1997).

New Zealand educator Fleming (1998) developed the Visual, Aural, Read/write, and Kinesthetic (also known as VARK) learning style model. This model and complimentary identification instruments classifies trainers by their preferred mode of interaction with students based on input stimulus and output preferences. In this study, VARK questionnaires are used to know the learning styles of students. This study is in regard to the preferred learning styles of various classes of TCHT and suggesting which one is the best instrument or combination of instruments which can be adopted in each class. The study clearly shows the different learning styles of various classes and how this information can improve teaching. 


\section{Literature Review}

Learning style fall in and out of fashion. They are regularly attacked by the academic literature and are targets of psychometricians. They seldom have statistics that rate them high for validity, reliability or predictions of future success. Instructional designers, educators and technologists alike need to understand how people learn so as to utilize the new information and communication technologies to effectively ensure the delivery of quality education for future generations (O'Brien, 2001).

The VARK instrument provides four styles of learning. According to Fleming, the most common mode of information exchange is speech that arrives at the learner's ear and therefore it is coded as Aural $(A)$ in the questionnaire. Some students reveal preferences for accessing information from printed words. This group is coded as Read or Write (R) since reading and writing are their preferred modes for receiving information. The third group of students are coded as Visual (V), since those students like information to arrive in the form of chart, graph, charts and flow diagrams. They prefer to learn pictured information or enhancing it with colors and layout. The last groups of students like to experience their learning using senses including touch, hearing, smell and sight. This group is coded as Kinesthetic (K). Learners from this group like concrete multi-sensory experiences in their learning. Abstract material must be presented to them with suitable analogs, real life examples, or metaphors. No student or teacher is restricted to resort to only one of the four modes. Problem based teaching uses a rich array of these modes and teachers may exhibit a strong preference for one particular mode or at the same time may have a number of combinations of learning preferences with relative strength or weakness in some other modes.

\section{Issues}

Fleming (1998) developed a questionnaire and used it at Lincoln University to identify the preferences of students for particular modes of information presentation.

In some search it was found that the teachers taught the way they learned in the past. On the contrary, a single teacher cannot provide useful guidelines for accommodating individual differences between learners while designing self instructional materials. 


\section{Objectives}

The main objectives of the study are as follows:

1. To know the preferred learning styles of various classes of kitchen technology of TCHT.

2. To check out the difference in learning style with regard to gender and class.

3. To know the various combination modes of learning styles students prefer.

4. To suggest, which is the best instrument, or combined instruments which can be, adopted in each class?

\section{VARK Learning Concept}

\section{V - Visual Learners}

To use visuals to explain things, like world-wide web pages that have strong graphics, hot boxes, diagrams, slides, charts, graphs, arrows, circles and boxes. The clever use of graphics, fonts, complex ideas to be shown first in a diagrammatic model. Important words and ideas are to be placed on the board so that they are spatially interesting.

\section{A - Aural Learners}

To use voice to explain things like tapes, conversations, phone calls, discussion in class, discussion of issues among themselves, to work together, and to contribute their ideas. The clever use of speech, making a point well, argument, discussion and debate, to say, to create written exams using these words-explain, describe, discuss and state, listen, speak, discuss, hear and comprehend are other learning methods.

\section{$R$ - Read/Write Learners}

The following are the favorite learning methods of these learners. To use written text to explain things, to give handouts and the clever usage of interesting words. Creating written exam questions using words such as define, justify, and analyze. The students to comprehend, understand, write, and define and to use words well. Students need to answer one-minute, write summaries, case studies, journals, formative quizzes, analytical lists efc. Students also review each other's notes (procedure) to enhance the teaching for read/write learners. 


\section{K - Kinesthetic Learners}

The learners prefer to use real life examples to explain things. Guest lectures, case studies, practical works, visits to sites and laboratories, exhibits, samples, newspaper stories, working models, products and people liked. The clever use of metaphors, examples and analogy in written work, bringing objects to class to make a point, role plays, demonstrations, practical tests, lab tests, lab reports and open book examinations, texts those are dense with cases, conversations, stories and biographies are their learning methods.

\section{Multimodal}

Those who prefer many modes are of two types. This is based on the occasion of learning procedures. They take longer time to gather information from each mode and as a result, they often have a deeper and broader understanding. VARK model helps participants to explore strategies into college reading and study skills instruction. A pedagogy which incorporates style led differentiation for individuals in the classroom (Riding and Rayner 1998) describes a lot on the aspects of student-centered learning.

\section{Conceptual Framework}

The conceptual framework derived from the study shows that based upon the target students' skills and knowledge, objectives and learning outcomes can be formulated for better curriculum development good choice of instrument of teaching should be formulated for achieving this and put into practice. The survey on VARK modes questionnaires help the teachers to accomplish the objectives and to operate the curriculum. The target students skills and knowledge are considered while formulating the objectives. Based on students learning style, appropriate teaching style is selected to operate the curriculum successfully (Figure 1). 


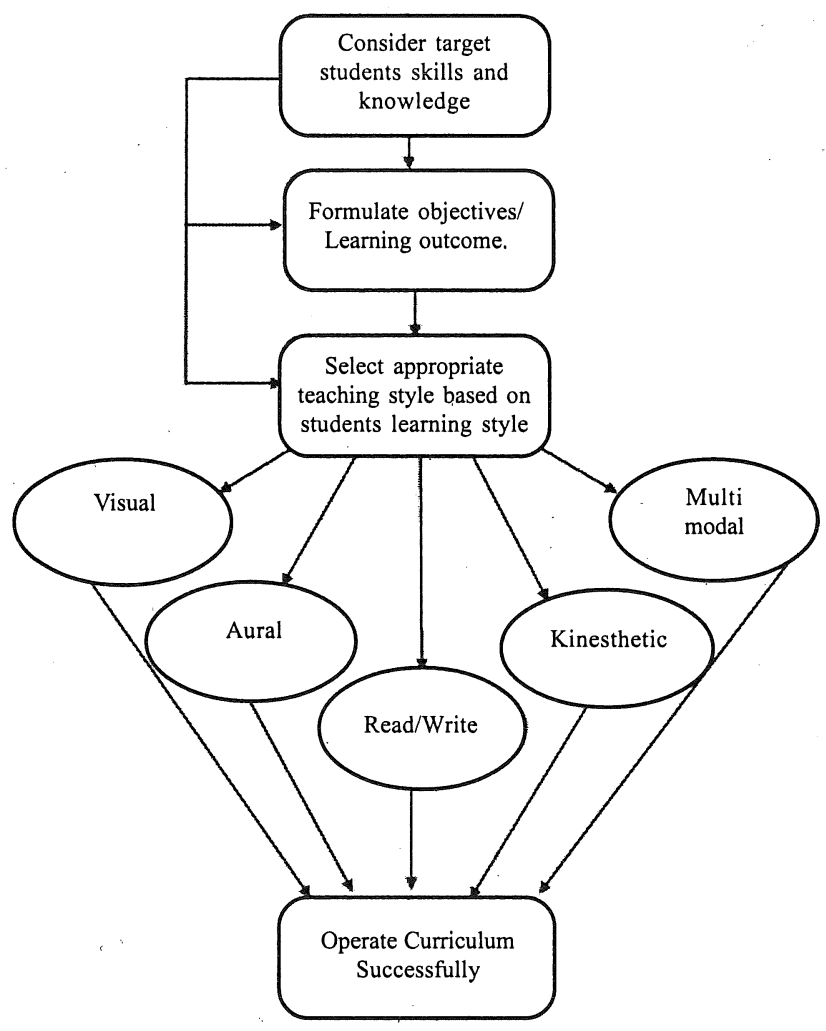

Figure 1: Conceptual Framework for Improving the Quality of Students Learning Style by Using VARK Instrument (source: Professor Henry Ellington, adapted from evaluating teaching and learning Process)

\section{Research Questions}

1. What are the key antecedents of learning styles which influence the learning outcomes that helps in the effective operation of course and curriculum?

2. Which dimension of learning has the maximum influence on students learning style? 


\section{Methodology}

The respondents were selected from TCHT department from the Higher diploma course of Hotel Management. Nine classes of students (approximately 17 students in a class) were part of the study. The respondents were of both genders. International students from various countries were also part of the study. The Non probability convenience sampling was employed for choosing the respondents. The questionnaire was given to 146 respondents and 145 were returned. Data was analyzed with Statistical Package for Social Science. Descriptive statistics were conducted to check the relationship between variables. The study was conducted among $63 \%$ of females and $37 \%$ of males.

The respondents ranked the preferred learning style they liked the most in the following order (See table 1)

Table 1: Rank Order of Preferred Learning Style

\begin{tabular}{|l|l|l|}
\hline S No & First Preference & Second Preference \\
\hline Group 1 & $\mathrm{K}(59 \%)$ & $\mathrm{R}(29 \%)$ \\
Group 2 & $\mathrm{K}(67 \%)$ & $\mathrm{R}(27 \%)$ \\
Group 3 & $\mathrm{A}(47 \%)$ & $\mathrm{V}(29 \%)$ \\
Group 4 & $\mathrm{K}(50 \%)$ & $\mathrm{A}, \mathrm{R}(25 \%)$ \\
Group 5 & $\mathrm{K}(50 \%)$ & $\mathrm{V}(38 \%)$ \\
Group 6 & $\mathrm{A}, \mathrm{K}(36 \%)$ & $\mathrm{R}(18 \%)$ \\
Group 7 & $\mathrm{A}, \mathrm{R}(31 \%)$ & $\mathrm{K}(23 \%)$ \\
Group 8 & $\mathrm{K}(41 \%)$ & $\mathrm{R}(335 \%)$ \\
Group 9 & $\mathrm{V}, \mathrm{A}, \mathrm{K}(31 \%)$ & $\mathrm{R}(6 \%)$ \\
\hline
\end{tabular}

Overall preference of learning style among female respondents. It was found that most of the female respondents were kinesthetic learners (42\%) followed by visual learners (30\%) (See Figure 2). 


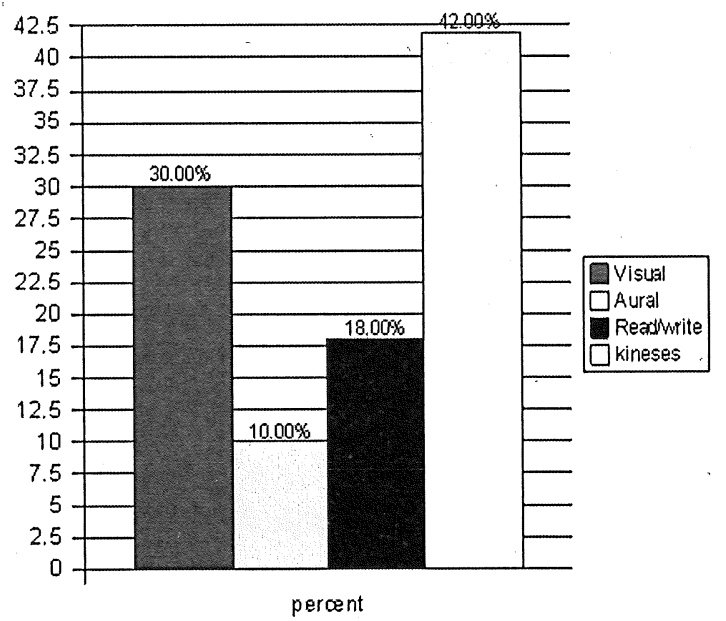

Figure 2: Overall preference among female respondents

Overall preference of learning style among male respondents. It was observed that most of the male were kinesthetic learners (40\%) followed by aural learners (25\%) (See Figure 3)

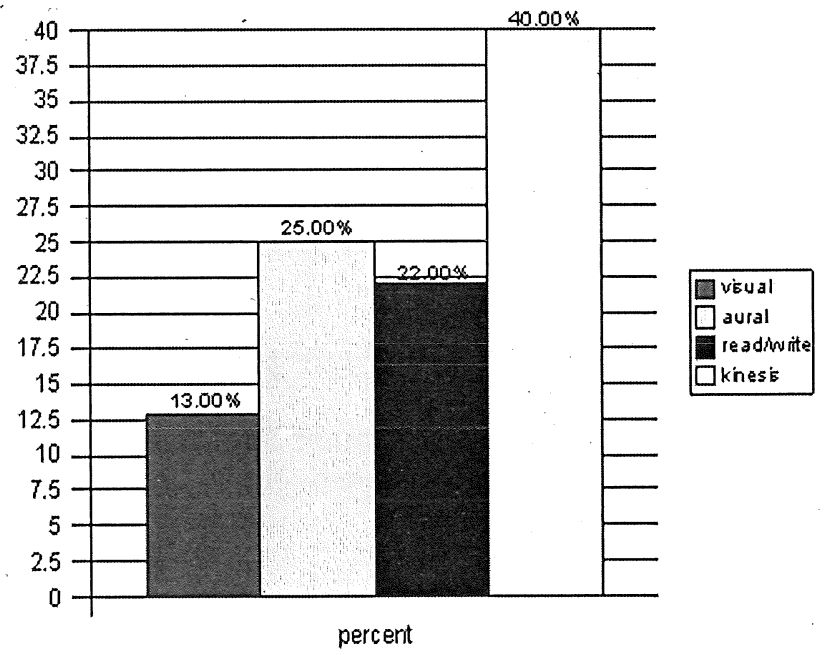

Figure 3: Overall preference among male respondents 


\section{Discussion and Findings}

From the above study, it was observed that the overall preferred learning style of students are Kinesthetic followed by Visual mode. The female respondents prefer Kinesthetic followed by Visual and the male respondents prefer Kinesthetic followed by Aural mode. It was found that all the groups prefer Kinesthetic while group 3 prefer Aural and group 7 prefers Aural and Reading. Group 9 preferred Visual, Aural and Kinesthetic. While dealing with combination modes it was found that the students preferred Visual-Kinesthetic followed by Aural-Reading.

The study resulted in saying that the students selected Kinesthetic mode of learning style as their first preference due to the professional approach of the course curriculum and they like the real hands-on experience while studying. Based upon the study, the teachers can adopt a combined mode of teaching practices of Visual, Aural, Read/Write and Kinesthetic in classes, if the students show Multimodal preferred learning styles. For the better delivery of classes the teachers can ask the students to fill up the VARK questionnaires and can deliver lectures based upon the class preferences. Based on this study teachers can adopt the most suitable teaching style to get better learning outcomes. The study says that the key antecedents of learning outcomes lay with the effectiveness of teaching methodologies that the teachers follow. The study shows that these teaching methodologies are directly linked to preferred learning styles of students which help them to get the maximum output of the lessons through their preferred model. The teachers can select the appropriate teaching style based on the preference of the class. The preferred learning style with maximum output in professional course like Hotel management is Kinesthetic. The study underlines this in accordance with the students preferred mode of learning style.

\section{Conclusion}

The usage of VARK instruments to know the preferred learning style of the students helps the students in various ways. Once the preferred learning style is identified the students go in for the various information technologies to support their studies. The student can record the video and audio lectures of the teachers in the classes. They can really go on with the various case study techniques based upon their preferred mode. This study was differed from the original study of the Fleming. This study's preferred learning styles of students are Kinesthetic and that of original study was Aural and Visual. This difference is because of the kind of programmes and the curriculum followed by the students. The study underlines the fact that the correct teaching pedagogy which goes along with the preferred learning style of students can give high inputs in the students learning outcomes. 


\section{References}

Swanson, J. (1995) Evaluating and assessing for learning, London: Kogan page.

Ellington, H. (1993) Evaluating teaching and learning process.London: CICED Publications.

Kirby, Patricia (1979) Cognitive style learning style and transfer skill acquisition, USA: The National Centre for Research in Vocational Education.

Fedler, Richard, M. Solom, Barbara, A. (1993) Learning styles and strategies, USA: North Carolina State University, Reston publishing.

Keeffe J.W. (1995) Profiting and utilizing learning style, National Association of Secondary Schools Principals Conference, New York: Praiger Publishers.

O'Brien, F. (2001) Learning style theory and its implication for the design and delivery of online education, Scottish educational review.

Brandt, D.S. (1996) Teaching the net: Innovative techniques in internet training Washington-ERIC NO.ED 412975

Fleming Neil. (1995) I am different, not dumb - modes of presentation (VARK) in the tertiary classroom, Australia, Development Society of Australia.

Garger, Sand Guid, P. (1984) Learning styles: The crucial difference, London, Curriculum Review Electronic Journal.

VARK for teachers http://www.jdentaled.org (accessed on $8^{\text {th }}$ September '08).

VARK homepage http:www.vark-learn.com (accessed on $8^{\text {th }}$ September '08).

Fleming Neil(1987) "VARK Multimodel strategy" http://varklearncom/questionnaire (accessed on $8^{\text {th }}$ September '08). 